\title{
Multiomics landscape of the autosomal dominant osteopetrosis type II disease-specific induced pluripotent stem cells
}

\author{
Chunhong $\mathrm{Li}^{1}$, Yu Shangguan ${ }^{2,3}$, Peng Zhu ${ }^{2}$, Weier Dai ${ }^{4}$, Donge Tang ${ }^{2 *}$, Minglin Ou ${ }^{1 *}$ and Yong Dai ${ }^{2^{*}}$ (D)
}

\begin{abstract}
Background: Autosomal dominant osteopetrosis type II (ADO2) is a genetically and phenotypically metabolic bone disease, caused by osteoclast abnormalities. The pathways dysregulated in ADO2 could lead to the defects in osteoclast formation and function. However, the mechanism remains elusive.

Materials and methods: To systematically explore the molecular characterization of ADO2, we performed a multiomics profiling from the autosomal dominant osteopetrosis type II iPSCs (ADO2-iPSCs) and healthy normal control iPSCs (NC-iPSCs) using whole genome re-sequencing, DNA methylation and N6-methyladenosine $(\mathrm{m} 6 \mathrm{~A})$ analysis in this study.

Results: Totally, we detected 7,095,817 single nucleotide polymorphisms (SNPs) and 1,179,573 insertion and deletions (InDels), 1,001,943 differentially methylated regions (DMRs) and 2984 differential m6A peaks, and the comprehensive multi-omics profile was generated from the two cells. Interestingly, the ISG15 m6A level in ADO2-iPSCs is higher than NC-iPSCs by IGV software, and the differentially expressed m6A-modified genes (DEMGs) were highly enriched in the osteoclast differentiation and p53 signaling pathway, which associated with the development of osteopetrosis. In addition, combining our previously published transcriptome and proteome datasets, we found that the change in DNA methylation levels correlates inversely with some gene expression levels.
\end{abstract}

Conclusion: Our results indicate that the global multi-omics landscape not only provides a high-quality data resource but also reveals a dynamic pattern of gene expression, and found that the pathogenesis of ADO2 may begin early in life.

Keywords: Osteopetrosis, Osteoclast, Whole genome sequencing, DNA methylation, N6-methyladenosine

*Correspondence: donge66@126.com; minglinou@163.com; daiyong22@aliyun.com

${ }^{1}$ Central Laboratory, Guangxi Health Commission Key Laboratory of Glucose and Lipid Metabolism Disorders, The Second Affiliated Hospital of Guilin Medical University, Guilin, Guangxi 541199, People's Republic of China

${ }^{2}$ Clinical Medical Research Center, Guangdong Provincial Engineering Research Center of Autoimmune Disease Precision Medicine, Shenzhen Engineering Research Center of Autoimmune Disease, The Second Clinical Medical College of Jinan University, The First Affiliated Hospital of Southern University of Science and Technology, Shenzhen People's Hospital, Shenzhen, Guangdong 518020, People's Republic of China Full list of author information is available at the end of the article

\section{Introduction}

Autosomal dominant osteopetrosis type II (ADO2) is a rare human inherited metabolic bone disease characterized by increased bone brittleness, mass and density due to osteoclast abnormalities [1-3]. It has a prevalence estimated at 1 in 20,000 live births, and usually occurs in late childhood or adolescence, but can also be detected in early infancy [2]. However, there is no curative therapeutics for ADO2 [4]. In most patients, they result from heterozygous mutations in CLCN7, which can result in nerve compression syndrome, 
visual loss and bone marrow failure, and may be presented diverse clinical and radiological manifestations ranging from asymptomatic or relatively mild symptoms to the very severe phenotype [2, 5]. Notably, some promising results suggest that small interfering RNA (siRNA)-based therapeutics may be used to cure patients with $\mathrm{ADO} 2$ and have been further demonstrated to be feasible in osteoporotic animal models $[6$, 7].

Currently, the integrative analysis of multi-omics has provided new ways for biomedical research, which can explain many complicated biological events associated with diseases [8-11]. Some evidence has strongly indicated that molecular changes at the DNA, RNA and protein levels could change the microenvironment of osteoclastogenesis, and lead to the defects in osteoclast formation and function $[1,12,13]$. To date, large-scale whole exome-sequenced studies of osteopetrosis have revealed more than 50 heterozygous mutations in the CLCN7 gene, which can lead to ADO2, among which the p.G215R has been studied extensively [13-15]. Ou and his colleagues have been identified a great number of miRNAs and proteins in the peripheral blood mononuclear cells from patients with osteopetrosis, and found that the changes in miRNA expression profiles suggest epigenetic variation [12]. A recent transcriptomic study has been suggested that changes in the expression of ITGB5, PRF1, WARS, and SERPINE2 may be part of the osteoclast phenotype, in addition to the acidification dysfunction caused by heterozygous mutations in the CLCN7 gene in osteoclasts in ADO2 patients [13]. In the past, knowledge about the molecular characterization and pathogenesis of osteopetrosis was primarily acquired by osteoporotic animal models [5, 16-19]. Recently, osteoporotic iPSC models were successfully generated from an ADO2 patient and three autosomal recessive osteopetrosis (ARO) patients, which has provided an unprecedented opportunity for the study of ADO2 pathophysiology and therapeutic application [1, 20, 21]. And thus, the molecular characterization of ADO2 is urgently to discover underlying biomarkers for osteopetrosis, facilitate early diagnosis, and accelerate the development of personalized therapeutics.

Here, we used the multi-omics combined with bioinformatics analysis to establish a multi-omics landscape, and observed a widespread epigenetic and transcription-regulatory pattern in the ADO2-iPSCs. In addition, our results indicate that the global multiomics landscape not only provides a high-quality data resource but also reveals a dynamic pattern of gene expression, and found that the pathogenesis of $\mathrm{ADO} 2$ may begin early in life.

\section{Materials and methods \\ Cell samples}

Written informed consent was obtained from the 31-year-old male participant who was diagnosed with ADO2 and was further confirmed to carry a mutation in CLCN7 (R286W). The urine cells of this participant were reprogrammed to generate ADO2-iPSC colonies, and the best colony was selected to construct the ADO2iPS cell line [1]. After the morphology of the cell line was identified, cells were collected, immediately transferred into liquid nitrogen and stored for future use. The healthy normal control iPSCs (NC-iPSCs) were provided by Cellapy Biotechnology (Beijing, China). This study was reviewed and approved by the Ethics Committee of Shenzhen People's Hospital (LL-KT-201801127).

\section{Whole genome library construction and sequencing}

Total DNA was extracted from autosomal dominant osteopetrosis type II iPSCs (ADO2-iPSCs) and normal control iPSCs (NC-iPSCs) using TIANamp Genomic DNA Kit (Cat. \#DP304-02, Lot\#03427, TIANGEN BIOTECH (BEIJING) CO., LTD) according to the manufacturer's protocol. Agarose gel electrophoresis was used to analyze the degree of DNA degradation and the presence of stray bands, RNA and protein contamination. The quantity of total DNA was measured by a NanoDrop 2000 spectrophotometer (Thermo Fisher Scientific, Inc., Waltham, MA, USA) and Qubit ${ }^{\circledR} 2.0$ Fluorometer (Thermo Fisher Scientific, Inc.), following which the total DNA samples with A260/280 ratios located range 1.8 to 2.0 were used for whole genome and DNA methylation library construction. The total DNA samples were randomly fragmented by a Covaris S220 Focused UItrasonicator (Covaris, Woburn, MA, USA) into $350 \mathrm{bp}$ fragments. The sheared products were detected by an Agilent 2100 Bioanalyzer system (Agilent, G2939AA). After the ends of the DNA fragments were repaired and an Illumina Adaptor was added, the PCR was used for whole genome library construction. And then, the qualified libraries were sequenced by an Illumina Novaseq ${ }^{\text {TM }}$ 6000 sequencer at LC-BIO (Hangzhou, China) with 150 base paired-end reads.

\section{SNPs and InDels detection and annotation}

The advanced bioinformatics analysis began with raw data generated from the NovaSeq6000 platforms. The sequence signatures with adapter ligation, low quality, and containing $>5$ unknown bases were removed to obtain clean sequences, which were subjected to further analysis. The clean sequences were aligned to the human reference genome (GRCh38) by a BurrowsWheeler Aligner (Version 0.7.8-r455) [22], and the alignment results were saved in BAM format files. For further 
advanced analysis of the final BAM files, single nucleotide polymorphisms (SNPs) and insertion and deletions (InDels) were detected by SAMtools (Version 1.0) [23]. Sambamba (Version 0.6.6) [24] was used to mark duplicate reads. Finally, ANNOVAR (Version 2017Jul16) [25] was used for annotation and classification.

\section{DNA methylated library construction and sequencing}

After total DNA extraction in the previous step, the DNA samples were randomly fragmented by a Covaris S220 Focused UItrasonicator (Covaris, Woburn, MA, USA) for end-repair and adapter ligation. The ends of the sheared DNA fragments were repaired and an Illumina Adaptor was added by using Accel-NGS Methyl-Seq DNA Library Kit (Swift, MI, USA), and then they were subjected to bisulfite conversion. After the PCR was performed, the products were purified using Bead-based SPRI and sequenced on an Illumina Hiseq 4000 sequencer at LCBIO (Hangzhou, China) with 150 base paired-end reads.

\section{DNA methylation differential analysis}

The raw sequencing datasets were initially processed by a perl scripts in house and Cutadapt [26], to remove the reads containing sequencing adaptors, low quality bases and undetermined bases. Then, the quality of expressed sequence tags was conducted using FastQC, and the valid reads were mapped to the human reference genome (GRCh38) by WALT [27]. And then, The DNA methylation levels were measured by the ratio of the number of reads supporting $C$ (methylated) to that of total reads (methylated and unmethylated). The differential methylated regions (DMRs) between the two cell lines were detected using R package-MethylKit according to $p$ value $<0.05$, and were subjected to performed volcano plot filtering, GO and KEGG enrichment pathway analyses.

\section{RNA methylated library construction and sequencing}

Total RNA was extracted from the two cell lines using TRIzol reagent (Invitrogen, CA, USA) according to the manufacturer's protocol. After total RNA extraction, four RNA methylated libraries were constructed as previously reported, with minor modifications [28]. Briefly, the quantity and purity of RNA samples were analyzed by a Bioanalyzer 2100 and RNA 6000 Nano LabChip Kit (Agilent, CA, USA) with RIN number > 7.0. Then, the Poly (A) mRNA was isolated from approximately more than 200 $\mu \mathrm{g}$ of total RNA using poly-T oligo attached magnetic beads (Invitrogen). Following purification, the poly(A) mRNA fractions is fragmented into $\sim 100$-nt-long oligonucleotides using divalent cations under elevated temperature. Then the sheared RNA fragments were subjected to incubated for $2 \mathrm{~h}$ at $4{ }^{\circ} \mathrm{C}$ with m6A-specific antibody (No. 202003, Synaptic Systems, Germany) in IP buffer $(50 \mathrm{mM}$ Tris- $\mathrm{HCl}, 750 \mathrm{mM} \mathrm{NaCl}$ and $0.5 \%$ Igepal CA-630) supplemented with BSA $(0.5 \mu \mathrm{g} \mu \mathrm{l}-1)$. The mixture was then incubated with protein-A beads and eluted with elution buffer $(1 \times \mathrm{IP}$ buffer and $6.7 \mathrm{mM} \mathrm{m} 6 \mathrm{~A})$. Eluted RNA was precipitated by $75 \%$ ethanol. Eluted m6A-containing fragments (IP) and untreated input control fragments are converted to final cDNA library in accordance with a strand-specific library preparation by dUTP method. The average insert size for the pairedend libraries was $\sim 100 \pm 50 \mathrm{bp}$. And then, the qualified libraries were sequenced by an Illumina Novaseq ${ }^{\mathrm{TM}} 6000$ sequencer at LC-BIO (Hangzhou, China) with 150 base paired-end reads.

\section{RNA methylation differential analysis}

The raw sequencing datasets were initially processed by a perl scripts in house and Cutadapt [26], to remove the reads containing sequencing adaptors, low quality bases and undetermined bases. Then, the quality of expressed sequence tags was conducted using FastQC, and the valid reads were mapped to the human reference genome (GRCh38) by HISAT2 [29]. Mapped reads of IP and input libraries were provided for $\mathrm{R}$ package exomePeak [30], which identifies m6A peaks with bed or bam format that can be adapted for visualization on the UCSC genome browser or IGV software (http://www.igv.org/). MEME [31] and HOMER [32] were used for de novo and known motif finding followed by localization of the motif with respect to peak summit by perl scripts in house. Called peaks were annotated by intersection with gene architecture using ChIPseeker [33]. Then StringTie [34] was used to perform expression level for all mRNAs from input libraries by calculating FPKM. The differentially expressed mRNAs were selected with log2 (fold change) $>1$ or $\log 2$ (fold change) $<-1$ and $p$ value $<0.05$ by $\mathrm{R}$ package edgeR [35].

\section{qRT-PCR analysis}

Quantitative real-time polymerase chain reaction (qRTPCR) was used to verify the identified mRNAs and miRNAs from the sequencing results in the ADO2-iPSCs and NC-iPSCs. Total RNA was extracted from the two cell lines described above and subjected to first-strand cDNA synthesis using the TRUEscript 1st Stand cDNA SYNTHESIS Kit (Aidlab, Beijing, China). The specific primers used in the qRT-PCR are listed in Table 1, and qRT-PCR was performed using a SYBR PrimeScript miRNA RT-PCR Kit (TianGen Biotech, Beijing, China). Each qRT-PCR mix was as follows: $5 \mu 12 \times$ SYBR $^{\circledR}$ Green Supermix, $0.5 \mu \mathrm{l}$ specific forward primer, $0.5 \mu \mathrm{l}$ specific reverse primer, $1 \mu \mathrm{l} \mathrm{cDNA}$ template and $3 \mu \mathrm{lddH} 2 \mathrm{O}$. The qRT-PCR procedure was as follows: $95^{\circ} \mathrm{C}$ for $3 \mathrm{~min}$ followed by $39 \mathrm{cycles}$ of $95^{\circ} \mathrm{C}$ for $10 \mathrm{~s}$ and $60^{\circ} \mathrm{C}$ for $30 \mathrm{~s}$, with 
Table 1 The primers using for PCR amplification

\begin{tabular}{|c|c|c|c|}
\hline NO. & Target & Sequence & $\mathrm{TM}\left({ }^{\circ} \mathrm{C}\right)$ \\
\hline 1 & ENST00000162749 & $\begin{array}{l}\text { F: CTGTACGCCGTGGTGGAGAAC } \\
\text { R:TCGTGGTCGCTCAGCCCTA }\end{array}$ & 60 \\
\hline 2 & ENST00000398795 & $\begin{array}{l}\text { F: ATCAGAGCAGAGAAAGCGATGG } \\
\text { R: GATGGGATGTCGGTGGCATTA }\end{array}$ & 60 \\
\hline 3 & ENST00000329608 & $\begin{array}{l}\text { F:TAGGCAACGAGCGACAGG } \\
\text { R:GTAGGGCAGGGTCTCTTAGC }\end{array}$ & 60 \\
\hline 4 & ENST00000316804 & $\begin{array}{l}\text { F: CTCCGACTCCAGATATGAACAG } \\
\text { R: GAGAAGCAGGATGAGGAAGAG }\end{array}$ & 60 \\
\hline 5 & ENST00000285379 & $\begin{array}{l}\text { F: GCCTCCTTCCTGAATCCTTGG } \\
\text { R: CTGATGGGTTCCTTGAGCACAA }\end{array}$ & 60 \\
\hline 6 & ENST00000382745 & $\begin{array}{l}\text { F: AGAAGGTCGGCGTCATTGTG } \\
\text { R: GGCAGGCTGGGTGTCATC }\end{array}$ & 60 \\
\hline 7 & ENST00000193322 & $\begin{array}{l}\text { F: GGTGGTAAGTGCCTGTAGTCCTA } \\
\text { R: GCAGTGGTACAATCTTGGCTCAT }\end{array}$ & 60 \\
\hline 8 & hsa-miR-29a-3p & $\begin{array}{l}\text { F: CGGCGGTAGCACCATCTG } \\
\text { R: GTCGTATCCAGTGCAGGGTCCGAGGTATTC } \\
\text { GCACTGGATACGACTAACCG }\end{array}$ & 60 \\
\hline 9 & hsa-miR-3165 & $\begin{array}{l}\text { F: TCGCAGGTGGATGCAATGT } \\
\text { R: GTCGTATCCAGTGCAGGGTCCGAGGTATTC } \\
\text { GCACTGGATACGACTGAGGT }\end{array}$ & 60 \\
\hline 10 & hsa-miR-410-3p & $\begin{array}{l}\text { F: GCGGCGGAATATAACACAGAT } \\
\text { R: GTCGTATCCAGTGCAGGGTCCGAGGTATTC } \\
\text { GCACTGGATACGACACAGGC }\end{array}$ & 60 \\
\hline 11 & hsa-miR-520h & $\begin{array}{l}\text { F: GGCGACAAAGTGCTTCCCT } \\
\text { R: GTCGTATCCAGTGCAGGGTCCGAGGTATTC } \\
\text { GCACTGGATACGACACTCTA }\end{array}$ & 60 \\
\hline 12 & hsa-miR-1226-3p & $\begin{array}{l}\text { F: GCGTCACCAGCCCTGTGT } \\
\text { R: GTCGTATCCAGTGCAGGGTCCGAGGTATTC } \\
\text { GCACTGGATACGACCTAGGG }\end{array}$ & 60 \\
\hline 13 & hsa-miR-373-5p & $\begin{array}{l}\text { F: TCAAAATGGGGGCGCTT } \\
\text { R: GTCGTATCCAGTGCAGGGTCCGAGGTATTC } \\
\text { GCACTGGATACGACGGAAAG }\end{array}$ & 60 \\
\hline 14 & hsa-miR-1343-3p & $\begin{array}{l}\text { F: TCTCCTGGGGCCCGC } \\
\text { R: GTCGTATCCAGTGCAGGGTCCGAGGTATTC } \\
\text { GCACTGGATACGACGCGAGA }\end{array}$ & 60 \\
\hline 15 & GAPDH & $\begin{array}{l}\text { F: TGCACCACCAACTGCTTAGC } \\
\text { R: GGCATGGACTGTGGTCATGAG }\end{array}$ & 60 \\
\hline 16 & U6 & $\begin{array}{l}\text { F: CTCGCTTCGGCAGCACA } \\
\text { R: AACGCTTCACGAATTTGCGT }\end{array}$ & 60 \\
\hline
\end{tabular}

Note: $F$, forward primer; $R$, reverse primer; $\mathrm{TM}$, annealing temperature

a melt curve analysis. GAPDH and U6 was used as an internal control gene for mRNAs and miRNAs, respectively. Three independent biological replicates were performed for each gene. The qRT-PCR data were analyzed by a comparative $2-\Delta \Delta \mathrm{Ct}$ method [36], and the average of three independent experiments for each gene was calculated as the relative expression level by GraphPad Prism (version 8.0.1).

\section{Western blotting}

ADO2-iPSCs and NC-iPSCs were homogenized in RIPA buffer (cat. no. KGP702-100; Changchun
Keygen Biological Products Co., Ltd.) containing protease inhibitor at $4{ }^{\circ} \mathrm{C}$, and then centrifuged at 16,000 $\mathrm{x} \mathrm{g}$ for $15 \mathrm{~min}$ at $4{ }^{\circ} \mathrm{C}$ to extract soluble protein. Protein extracts were quantified using the $\mathrm{BCA}$ method and loaded on $12 \%$ SDS-gels ( $20 \mu \mathrm{g}$ per lane), resolved using SDS-PAGE, and then transferred to nitrocellulose membranes. Following blocking (5\% skim milk) for $2 \mathrm{~h}$ at room temperature, membranes were incubated overnight at $4{ }^{\circ} \mathrm{C}$ with primary antibodies against CLC-7 (1:1000), or $\alpha$-tubulin (1:2000). Subsequently, the membranes were incubated with HRP-conjugated anti-rabbit secondary antibody $(1: 1000)$ at room temperature for $2 \mathrm{~h}$. Signals were visualized using a Quantity One 
system image analyzer (Bio-Rad Laboratories, Inc.) and densitometry analysis was performed using Image J.

\section{Results}

\section{Gene variation profiling}

Genomic DNA was extracted from the two cell lines and sequenced on the Illumina Novaseq ${ }^{\mathrm{TM}} 6000$ platform. A total of $223.83 \mathrm{G}$ raw data was generated, and an average of 373,042,278 raw reads for each cell line (Table S1). The raw reads with adapters, low quality and unknown bases were removed, and we collected clean reads for further statistical analysis. The numbers of clean reads were 664,170,002 and 827,969,924 for ADO2-iPSCs and NC-iPSCs, of which 99.87 and $99.87 \%$, respectively, were accurately aligned to the reference genome (GRCh38) (Table S2). In the ADO2-iPSCs and NC-iPSCs, the sequence depth and coverage of bases are in line with Poisson distribution, and the average depth and coverage of each chromosome of the reference genome (GRCh38) are shown in Fig. 1.

Upon further bioinformatics analysis for clean reads, we identified 3,553,239 and 3,542,578 SNPs for ADO2iPSCs and NC-iPSCs, and $1.8 \%(62,715$ and 62,418$)$ of these were located in exotic regions. Most SNPs within protein-coding regions were synonymous and missense. Similarly, there were 583,522 and 596,051 InDels for ADO2-iPSCs and NC-iPSCs, and 1.2\% (7152 in $583,522,7113$ in 596,051) of these were located in exotic regions (Fig. 1). We next filtered the core osteoporotic genes that were involved in hsa04380 Osteoclast differentiation as candidate genes (Table S3), and they were further confirmed by Sanger sequencing, and Western blotting analysis, such as CLCN7 gene (Fig. 1).

\section{DNA methylation profiling}

To explore the methylation status of ADO2-iPSCs, we sequenced and analysed genome-wide DNA methylation levels of ADO2-iPSCs and NC-iPSCs. In total, 602,933,334 and 601,600,002 raw reads for ADO2-iPSCs and NC-iPSCs were generated, of which 598,992,532 and 598,060,246 valid reads were used for further bioinformatics analysis (Table S4 and S5). The overall DNA methylation levels of $\mathrm{mCpG}, \mathrm{mCHG}$ and $\mathrm{mCHH}$ in the two cell lines were presented in Fig. 2. The figure showed that DNA methylation levels of ADO2-iPSCs were similar to NC-iPSCs. According to the $1000 \mathrm{bp}$ windows, 500 bp overlap and $P<0.05$, we identified $1,001,943$ differentially methylated regions (DMRs). Among these DMRs, 856,823 DMRs were identified as hyper-methylated regions, and 145,120 DMRs were identified as hypo-methylated regions (Fig. 2). Further bioinformatic analysis of the 1,001,943 differentially methylated regions showed that this candidate methylated genes were implicated in various biological functions, and the top $20 \mathrm{GO}$ terms and pathways were presented in Fig. 2. Go enrichment analysis revealed that these differentially expressed methylated genes were highly enriched voltage-gated calcium channel complex and actin cytoskeleton. They are mainly enriched in the following genes: CACNA1S; AC068547.1; CACNA1D; CACNA2D1; CACNA1F; CACNA1B; CACNB2; CACNA2D4; CACNA1G; CACNG4; CACNG1; CACNA1A; CACNG2; LAD1; MPP4; TMEM63B; FILIP1; AC004922.1; ARPC1B; ZNF185; ACTL7B; LSP1; LIMA1; CORO1C; LCP1; DSTN; PDXP.

\section{m6A methylation profiling}

Like DNA modification, N6-methyladenosine (m6A) is a novel RNA modification that has been extensively studied in plants and animals [28]. To explore the m6A modification levels of ADO2-iPSCs, we sequenced and analysed genome-wide RNA methylation levels of ADO2-iPSCs and NC-iPSCs. In total, the two cell lines were obtained $71,051,686$ and 79,256,816 raw data reads, $68,539,884$ and $77,263,294$ valid reads, and the valid reads accounted for 80.10 and $81.45 \%$, of which the mapping ratio of valid reads in the ADO2-iPSC library and NC-iPSC library were 91.12 and $92.97 \%$ in the m6A-seq libraries, respectively. In the RNA-seq library, the two cell lines were obtained 40,503,394 and 46,238,982 raw data reads, 39,422,992 and 45,409,718 valid reads, and the valid reads accounted for 93.84 and $95.23 \%$, of which the mapping ratio of valid reads in the ADO2-iPSC library and NC-iPSC library were 95.28 and $97.09 \%$, respectively (Table S6 and S7). And the regional location of mapped reads is shown in Supplementary Fig. 1. Next, the m6A peaks were further annotated using the ChIPseeker software. And according to $P<0.05$, we identified only 2984 differential m6A peaks. Among these peaks, 1142 were upregulated and 1842 were downregulated, and the regional location of differential m6A peaks is shown in Fig. 3. Intensive sequence motif analysis for 2984 differential m6A peaks was carried out, and the top five motifs with the smaller $p$-value were presented in the Fig. 3.

And then, the expression abundance of gene was calculated by FPKM. In total, 28,078 m6A-methylated genes were identified, among which 652 m6A-methylated genes were differentially expressed between the two cell lines, and the box plot and of all m6A-methylated gene expression are showed in Figs. 3. According to the $\mid \log 2$ (fold change) $\mid>1$ and $p$ value $<0.05$ criteria, 367 m6A-methylated genes were upregulated and 285 m6A-methylated genes were downregulated, and the volcano plot filtering of the differentially expressed m6A-methylated genes (DEMGs) is presented in Fig. 3. Interestingly, the downregulated genes ISG15 


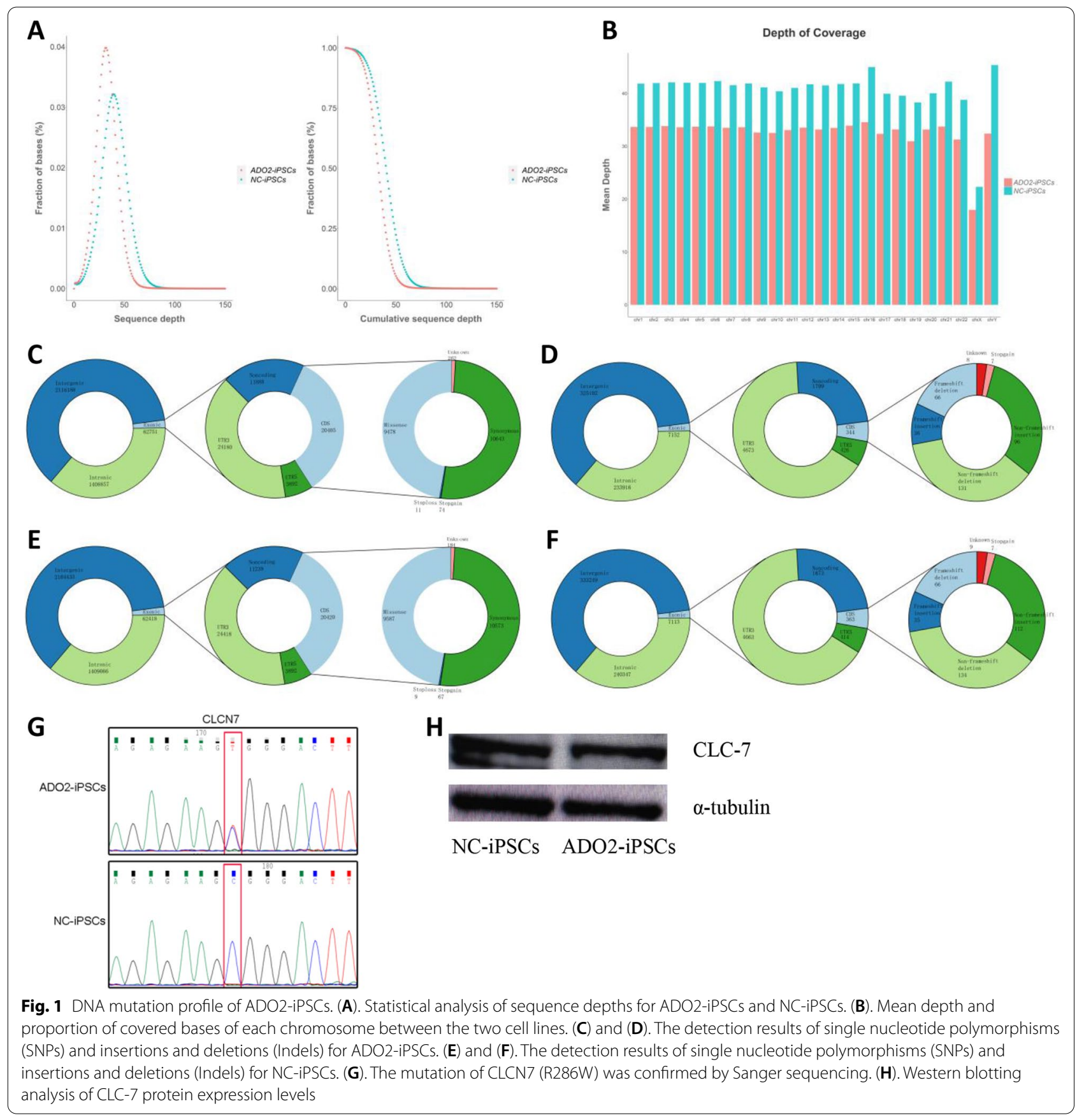

m6A level in ADO2-iPSC sample is higher than NCiPSC as shown in Figs. 3 by IGV software. Then, we further gathered the 652 DEMGs to conduct GO and KEGG pathway enrichment analyses and found that their biological functions were diverse, and the top 20 significantly GO enrichment terms and enriched pathways were presented in Fig. 3. KEGG pathway enrichment analysis revealed that these DEMGs were highly enriched in the osteoclast differentiation and p53 signalling pathway, which associated with the development of osteopetrosis. In addition, the pathway of osteoclast differentiation is mainly involved in the following candidate genes: CREB1; FOSL1; FOSL2; GAB2; JUNB; MAPK14; PIK3R1; PLCG2; SOCS3. And the FoxO signaling pathway is mainly involved in the following candidate genes: BCL2L11; BCL6; BNIP3; CDKN1A; GADD45B; MAPK14; PDPK1; PIK3R1; RAG1; Z98749.3. 

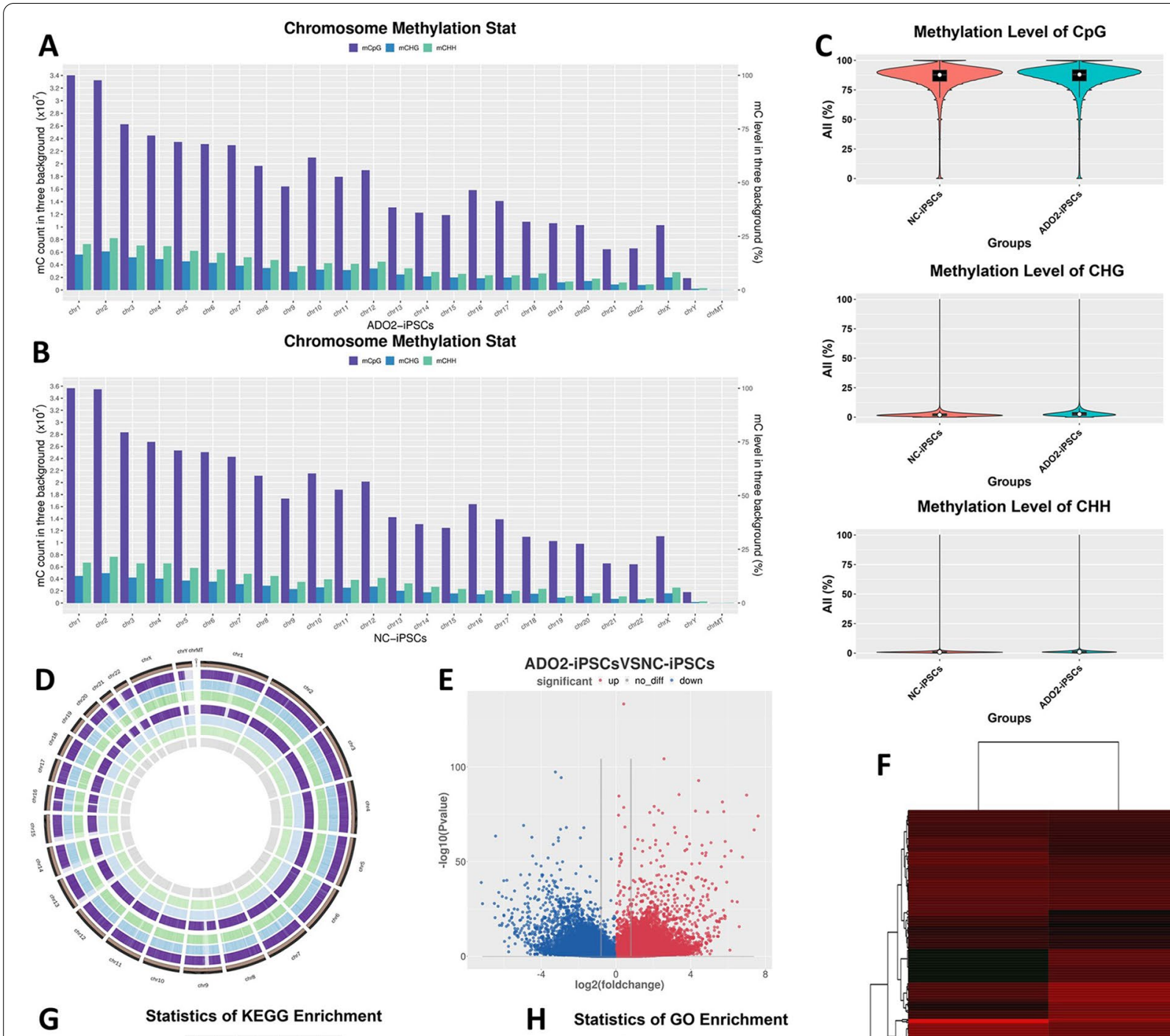

H Statistics of GO Enrichment
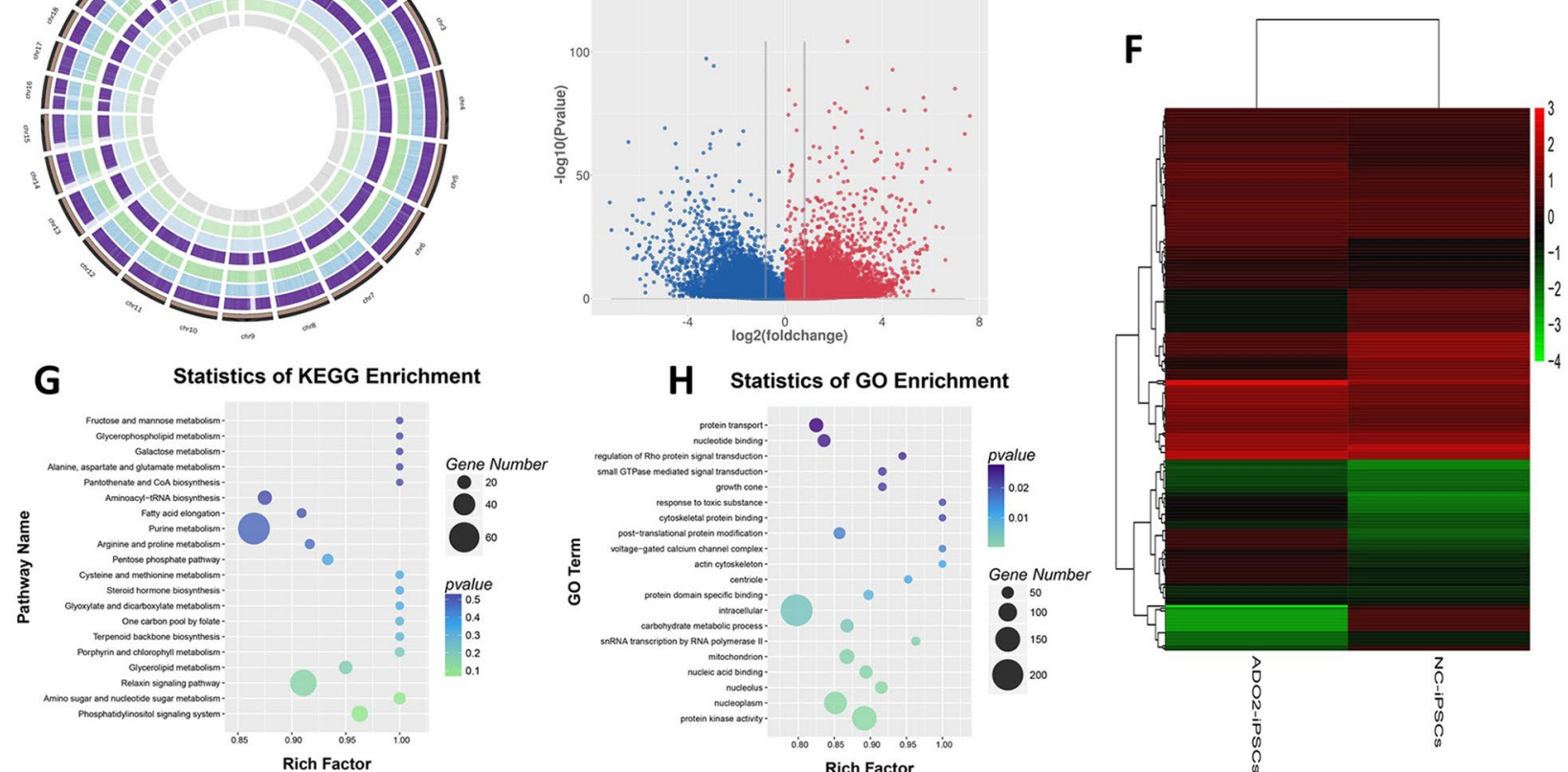

Fig. 2 Genome-wide DNA methylation landscape of ADO2-iPSCs. (A) and (B). The distribution of CpG, CHG and CHH methylation on chromosome for ADO2-iPSCs and NC-iPSCs, respectively. (C). The violin plots of $\mathrm{CpG}, \mathrm{CHG}$ and $\mathrm{CHH}$ methylation levels. (D). Circos plots of $\mathrm{CpG}, \mathrm{CHG}$ and $\mathrm{CHH}$ methylation levels. (E). Volcano plot of differentially expressed methylated genes. (F). Clustered heat map of differentially expressed methylated genes between ADO2-iPSCs and NC-iPSCs. (G). KEGG pathway enrichment analysis of differentially expressed methylated genes. (H). GO enrichment analysis $s$ of differentially expressed methylated genes 


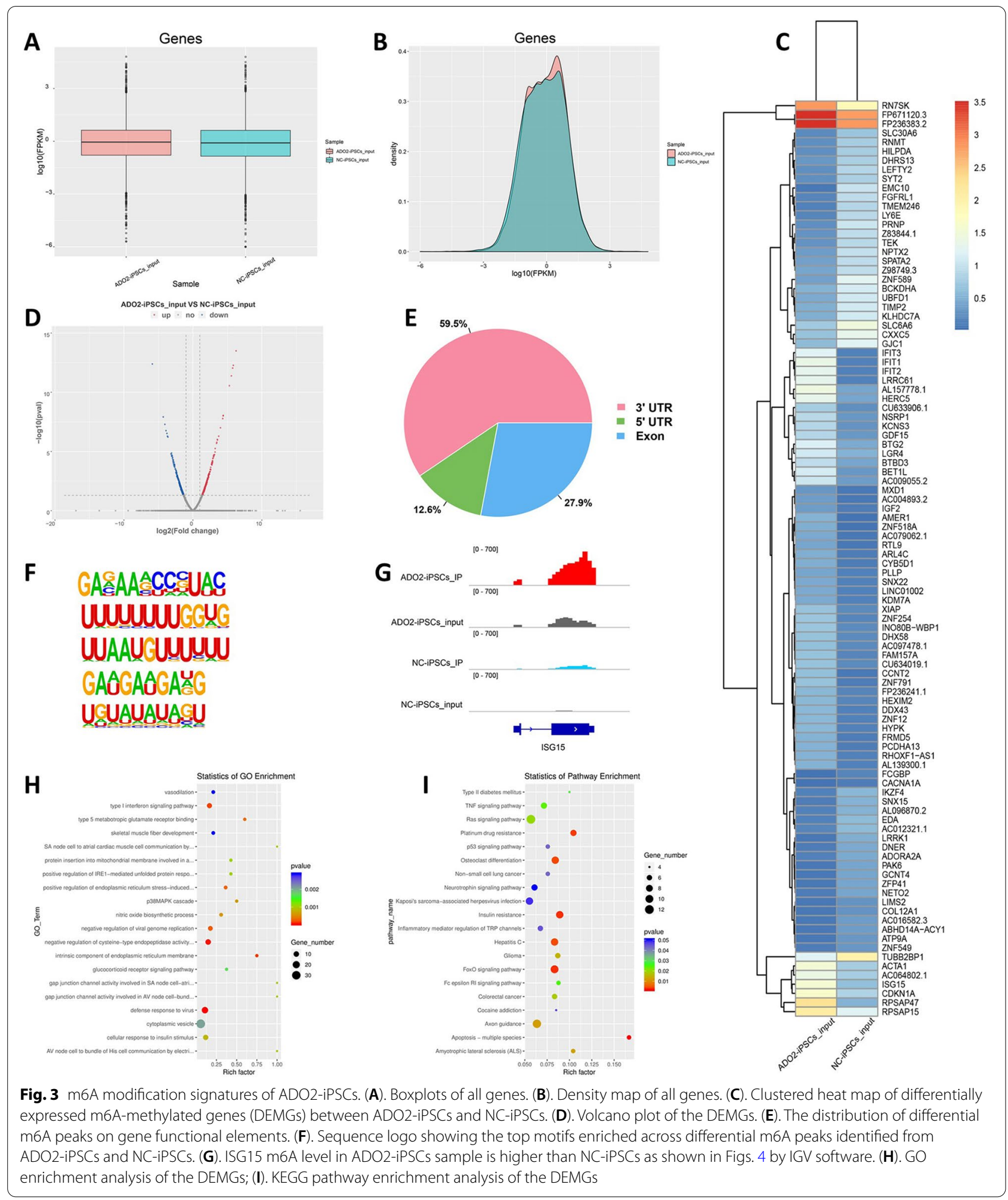

\section{ceRNA regulatory networks}

To investigate the role of non-coding RNAs in the ADO2-iPSCs, we performed the deep RNA-seq from
ADO2-iPSCs and NC-iPSCs to obtain the differential expression profiles of circRNAs, lncRNAs and miRNAs and mRNAs in our previous study. We next used 


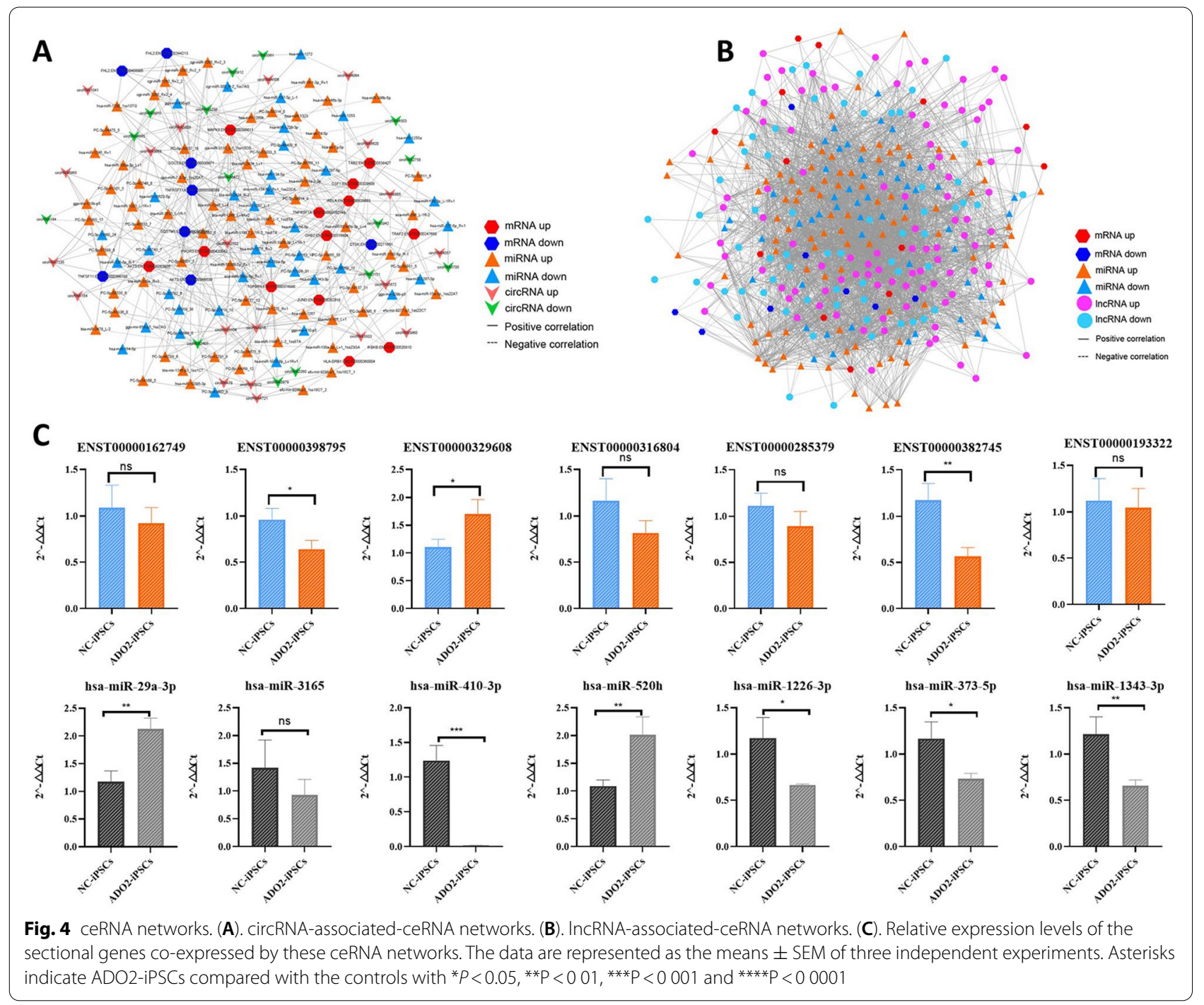

TargetScan (v. 5.0) and miRanda (v. 3.3a) to identify circRNA-miRNA, miRNA-mRNA and lncRNA-miRNA interactions for the construction of ceRNA regulatory network. According to the ceRNAs theory, the relative expressions of miRNAs should be negatively correlated with relative expressions of targeted circRNA/lncRNAs and mRNAs. Therefore, we overlapped the predicted targeting relationships of up-regulated miRNAs with down-regulated circRNA/lncRNAs and mRNAs, and overlapped the predicted targeting relationships of down-regulated miRNAs with up-regulated circRNA/ lncRNAs and mRNAs. Finally, we used the Cytoscape (v. 3.5.0) to construct ceRNA regulatory networks that contained two parts: 1). the circRNA-associated-ceRNA networks, which included 15 upregulated circRNAs, 38 downregulated miRNAs and 13 upregulated mRNAs, as well as 20 downregulated circRNAs, 69 upregulated miRNAs and 8 downregulated mRNAs; 2). the
lncRNA-associated-ceRNA networks, which included 97 upregulated lncRNAs, 53 downregulated miRNAs and 13 upregulated mRNAs, as well as 63 downregulated lncRNAs, 96 upregulated miRNAs and 8 downregulated mRNAs (Fig. 4). In addition, the sectional genes co-expressed by these ceRNA networks were further confirmed by qRT-PCR, and the results showed that the relative expression of genes was basically consistent with the results of high-throughput sequencing (Fig. 4).

\section{Proteomic profiling}

To understand the molecular characterization of ADO2, we performed an in-depth proteomic profiling from the two cell lines to obtain the differential expression profiles of proteins and $\mathrm{K}_{\mathrm{hib}}$-modified proteins in our previous research [1]. Further advanced intersection analysis for 177 differentially expressed proteins (DEPs) and 410 differentially expressed $\mathrm{K}_{\mathrm{hib}}$-modified proteins (DEKMPs), 
Table 2 Summary of the candidate proteins from proteomic profile

\begin{tabular}{|c|c|c|c|c|c|c|}
\hline Index & Protein accession & Protein description & Fold change & Up/ down & P value & Gene name \\
\hline 1 & P22234 & $\begin{array}{l}\text { Multifunctional protein ADE2 OS=Homo sapiens OX }=9606 \\
\text { GN=PAICS }\end{array}$ & 0.8 & Down & 0.000035892 & PAICS \\
\hline 2 & P06727 & Apolipoprotein A-IV OS=Homo sapiens OX $=9606 \mathrm{GN}=\mathrm{APOA} 4$ & 0.7 & Down & 0.035622 & APOA4 \\
\hline 3 & P12268 & $\begin{array}{l}\text { Inosine }-5^{\prime}-\text { monophosphate dehydrogenase } 2 \mathrm{OS}=\text { Homo sapiens } \\
\mathrm{OX}=9606 \mathrm{GN}=\mathrm{MPDH} 2\end{array}$ & 0.814 & Down & 0.00060007 & IMPDH2 \\
\hline 4 & P40925 & $\begin{array}{l}\text { "Malate dehydrogenase, cytoplasmic OS=Homo sapiens } \\
\mathrm{OX}=9606 \mathrm{GN}=\mathrm{MDH} 1 "\end{array}$ & 0.794 & Down & 1.2969E-09 & $\mathrm{MDH} 1$ \\
\hline 5 & P30566 & Adenylosuccinate lyase OS=Homo sapiens OX $=9606 \mathrm{GN}=\mathrm{ADSL}$ & 0.692 & Down & $1.7211 \mathrm{E}-09$ & ADSL \\
\hline 6 & P55209 & $\begin{array}{l}\text { Nucleosome assembly protein 1-like } 1 \text { OS=Homo sapiens } \\
\text { OX }=9606 \mathrm{GN}=\text { NAP1L1 }\end{array}$ & 0.796 & Down & 0.027664 & NAP1L1 \\
\hline 7 & Q8WUM4 & $\begin{array}{l}\text { Programmed cell death 6-interacting protein OS=Homo sapiens } \\
\text { OX }=9606 \mathrm{GN}=\text { PDCD6IP }\end{array}$ & 0.764 & Down & 0.00058313 & PDCD6IP \\
\hline 8 & Q96KP4 & $\begin{array}{l}\text { Cytosolic non-specific dipeptidase OS=Homo sapiens OX }=9606 \\
\text { GN=CNDP2 }\end{array}$ & 0.792 & Down & $1.0982 \mathrm{E}-06$ & CNDP2 \\
\hline 9 & P06744 & $\begin{array}{l}\text { Glucose-6-phosphate isomerase OS=Homo sapiens OX =9606 } \\
\text { GN=GPI }\end{array}$ & 0.81 & Down & $3.2818 \mathrm{E}-08$ & GPI \\
\hline 10 & P00558 & $\begin{array}{l}\text { Phosphoglycerate kinase } 1 \text { OS=Homo sapiens OX }=9606 \\
\text { GN=PGK1 }\end{array}$ & 0.798 & Down & $2.48268 \mathrm{E}-12$ & PGK1 \\
\hline 11 & Q9Y678 & $\begin{array}{l}\text { Coatomer subunit gamma-1 OS=Homo sapiens OX }=9606 \\
\text { GN=COPG1 }\end{array}$ & 1.523 & Up & 0.00020409 & COPG1 \\
\hline 12 & P02545 & Prelamin-A/C OS=Homo sapiens OX $=9606 \mathrm{GN}=\mathrm{LMNA}$ & 1.3 & Up & $6.8335 \mathrm{E}-10$ & LMNA \\
\hline 13 & P00338 & $\begin{array}{l}\text { L-lactate dehydrogenase } A \text { chain OS=Homo sapiens OX }=9606 \\
\text { GN }=\text { LDHA }\end{array}$ & 0.73 & Down & $2.13718 \mathrm{E}-13$ & LDHA \\
\hline 14 & P18669 & $\begin{array}{l}\text { Phosphoglycerate mutase } 1 \text { OS=Homo sapiens OX }=9606 \\
\text { GN=PGAM1 }\end{array}$ & 0.772 & Down & $3.5611 \mathrm{E}-06$ & PGAM1 \\
\hline 15 & P63167 & $\begin{array}{l}\text { "Dynein light chain 1, cytoplasmic OS=Homo sapiens OX = } 9606 \\
\text { GN=DYNLL1" }\end{array}$ & 0.813 & Down & 0.0032784 & DYNLL1 \\
\hline
\end{tabular}

we collected 15 DEPs with differentially $\mathrm{K}_{\mathrm{hib}}$-modified sites as candidate proteins for additional analysis (Table 2). We next gathered the 15 candidate proteins to perform GO and KEGG pathway enrichment analysis. The majority of GO terms including the candidate proteins are presented in Fig. S2. In the cellular component, the candidate proteins were highly enriched in cytosol (GO:0005829). In the biological process, the terms of nucleoside phosphate metabolic process (GO:0006753), ribose phosphate metabolic process (GO:0019693) and oxidoreduction coenzyme metabolic process (GO:0006733) were the most enriched. For the KEGG pathway analysis, the only one significantly enriched pathway (hsa00010 Glycolysis / Gluconeogenesis) were identified for these candidate proteins (Supplementary Fig. 2). The regulation network among the candidate proteins, DEPs and DEKMPs were constructed as a whole, and the interaction between them may affect the pathogenesis of osteopetrosis (Fig. 5).

\section{Integration analysis of multi-omics datasets}

Some evidence indicated that the methylation changes were negatively correlated with gene expression [8]. And thus, we overlapped the up-regulated DMRs with down-regulated mRNAs and proteins, and overlapped the down-regulated DMRs with up-regulated mRNAs and proteins. Indeed, we found that up-regulated DMRs with were significantly associated with anticorrelated gene expression in the ADO2-iPSCs (Supplementary Fig. 3). In addition, pairwise comparisons indicated a global positive correlation between transcription and proteome (Fig. 6). Further intersection analysis for four omics, including whole genome re-sequencing, DNA methylation, whole transcriptome sequencing and N6-methyladenosine, we collected 201 overlapped genes for bioinformatics analysis. Gene ontology (GO) enrichment analysis indicated that the overlapped genes were significantly enriched in protein binding, nucleus, membrane, cytoplasm and cytosol. In addition, KEGG pathway enrichment analysis revealed that the overlapped genes were mainly enriched in cell adhesion molecules (CAMs), Protein processing in endoplasmic reticulum, and Autophagy-animal (Fig. 6). Interestingly, the pathway of cell adhesion molecules is mainly involved in the following overlapped genes: SDC3, ITGA6, HLA-A, CD276, $\mathrm{CDH} 3$, and PVR. The pathway of protein processing in endoplasmic reticulum is mainly involved in the following overlapped genes: SSR1, CAPN1, HSP90AA1, 


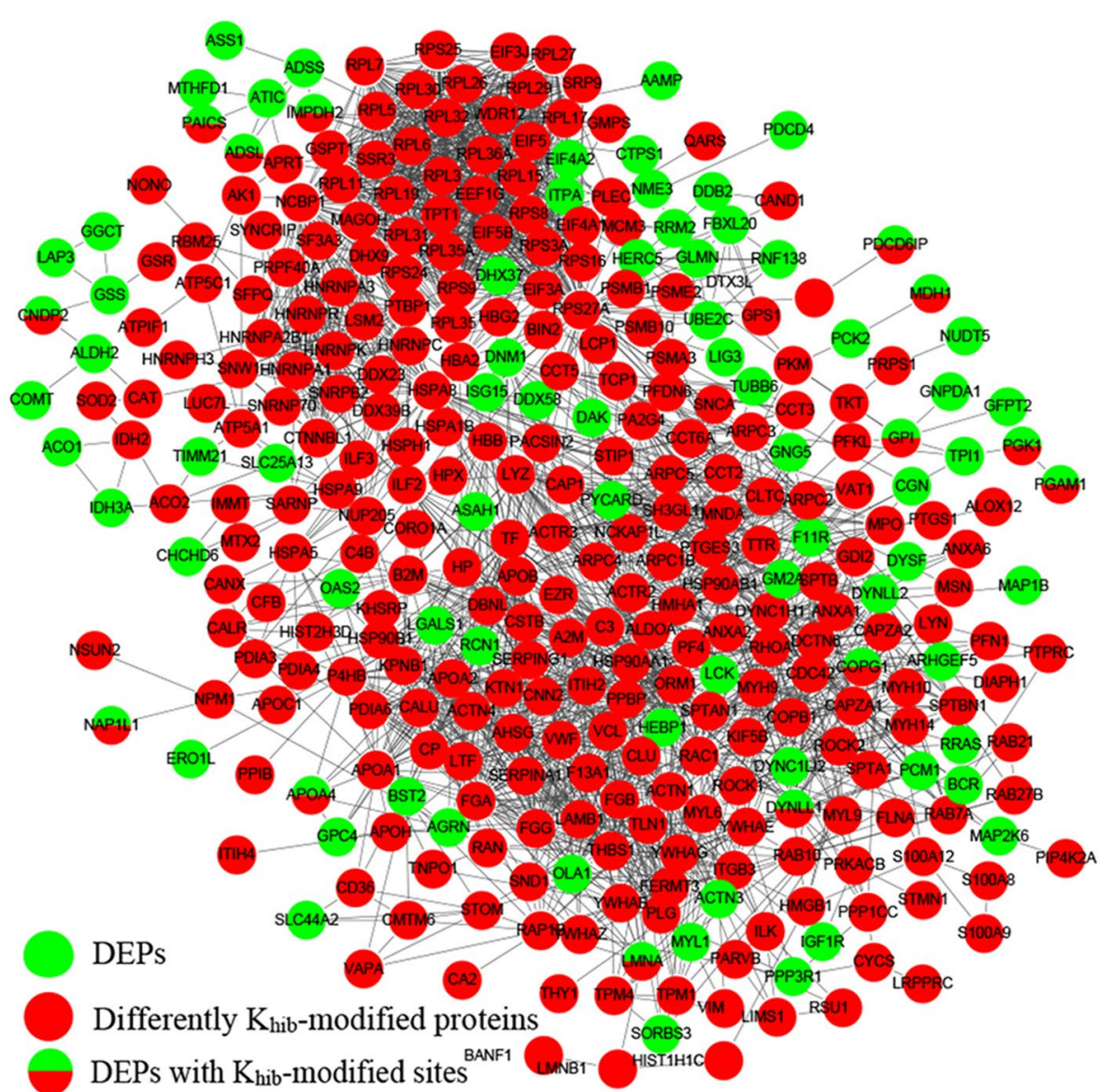

Fig. 5 The potential regulatory network among the candidate proteins, DEPs and DEKMPs

EIF2AK4, NSFL1C. And the pathway of Focal adhesion is mainly involved in the following overlapped genes: ITGA6, FLNB, MYLK, FLNA.

\section{Discussion}

Autosomal dominant osteopetrosis type 2 (ADO2) is one of the rarest human inherited bone diseases that is characterized by osteoclast abnormalities, and the clinical manifestations of ADO2 extend beyond the skeleton, affecting several other organs, such as brain, lungs, kidneys and muscles [2, 37]. The pathogenesis of ADO2 remains elusive due to the lack of clinical samples and mouse models, and there is no specialized treatment for human CLCN7-dependent ADO2 [16]. Recently, the autosomal dominant osteopetrosis type 2 disease-specific induced pluripotent stem cells (ADO2-iPSCs) were generated, which carried the same genetic background with the ADO2 patients and may be a useful tool for ADO2 studies [1]. Some evidence has strongly indicated that gene expression changes affecting cellular processes in human diseases are also present in these undifferentiated disease-specific iPSCs [38-41]. For example, Chae et al. performed quantitative proteomic analysis of HDiPSC derived from a human Huntington's (HD) disease patients, and they found that the undifferentiated HDiPSCs provided valuable information to understand the pathogenesis of HD [38]. Szlachcic and colleagues performed another study on the naïve mouse HD YAC128 iPSCs and two types of human HD iPSC generated from HD and juvenile-HD patients, they found that a number of changes affecting cellular processes in HD were also present in undifferentiated HD-iPSCs [39]. In addition, as far as we know, this is the first time that we have used an osteopetrotic iPSC model (ADO2-iPSCs) to explore the pathogenesis of osteopetrosis [1], and found that protein expression changes affecting osteoclast function were also present in undifferentiated ADO2-iPSCs, and the pathogenesis of ADO2 may begin early in life. It may be a very interesting point for our future study using the generated ADO2-iPSCs. However, there are the following limitations for the samples in this study: firstly, we have limited number of patients with ADO2 in the 


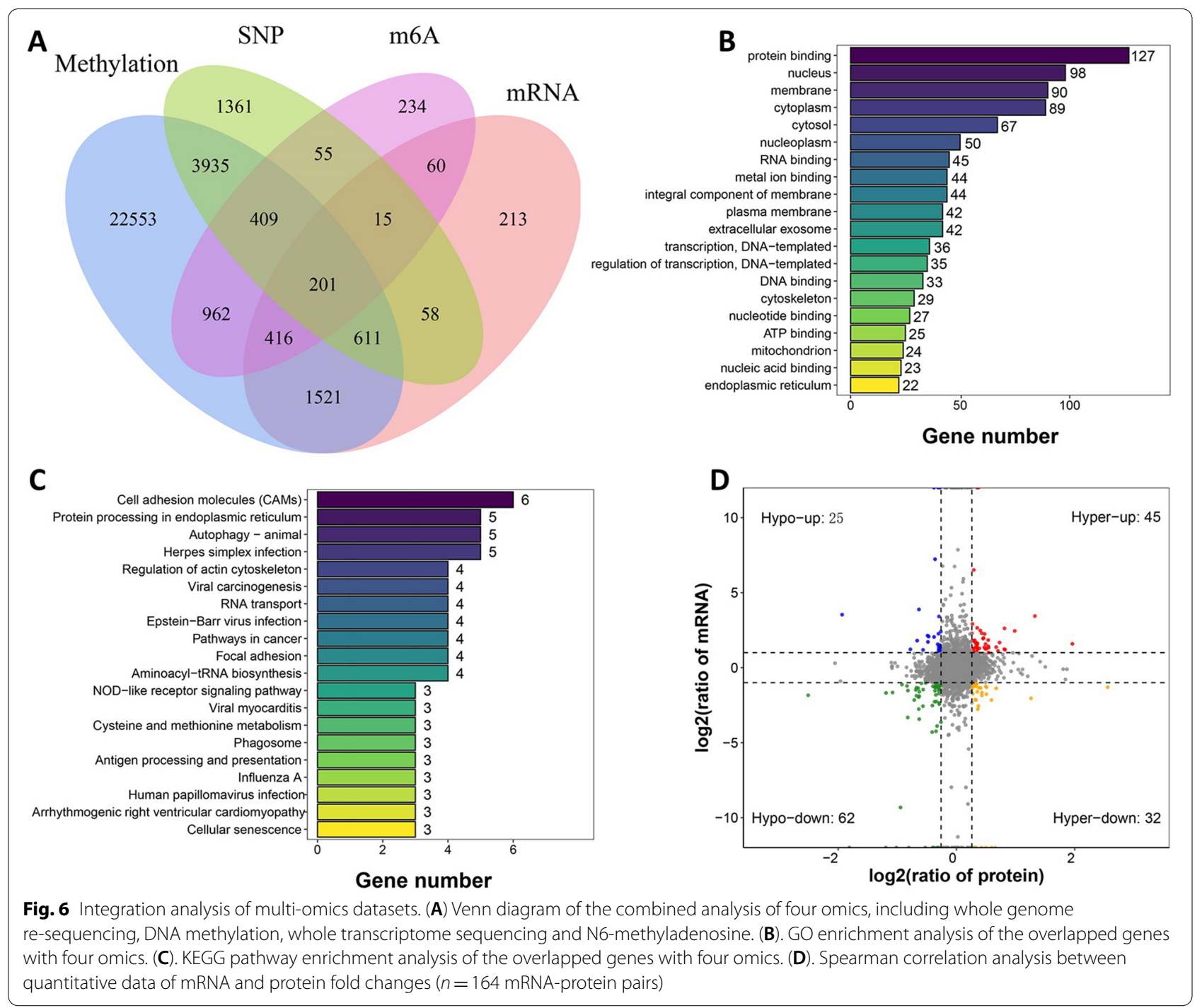

orthopedics department of Shenzhen People's Hospital [1]; secondly, we have very restricted criteria for volunteer recruitment, and all participants were clinically identified and diagnosed according to the standard spine and pelvis radiographs and genotyping. Therefore, this was a reason that the sample size of ADO2-iPSCs group is smaller.

It is noteworthy that the susceptibility in human genetic disease is commonly associated with DNA mutations, such as single nucleotide polymorphisms (SNPs) and insertion and deletions (InDels). In this study, we detected the vast majority of DNA mutations from the ADO2-iPSCs, including SNPs and Indels, which may affect protein structure and stability. Some models were developed for determining the mechanism of each DNA mutation at the protein level base on the vitro mutagenesis studies and the protein structural context of each mutation [42]. Approximately $90 \%$ of the known diseasecausing missense mutations affected protein stability through a variety of energy related factors, which may be playing important roles in the pathologic processes of diseases [42]. ADO2 is a typical human genetic disease, and dozens of studies have indicated that the mutation CLCN7 (R286W) is a disease-causing heterozygous mutation in many osteopetrosis families [15, 43], and confirmed by Sanger Sequencing in our present study. From the literature of the mutation CLCN7 (R286W), we can learn that the mutation CLCN7 (R286W) may lead to the defects in translations of $\mathrm{ClC}-7$, and the affected amino acid is R286. However, there was no difference in the expression of $\mathrm{ClC}-7$ between the two cell lines in the proteomic profile, so we speculated that the heterozygous mutation of CLCN7 (R286) might not affect its expression and might change its protein structure. 
Although almost all of the published studies are based on the data of DNA sequencing and bioinformatics analysis, it may be reasonable to believe that defect in translation is one of the most important cause of osteopetrosis. Furthermore, the proteomic profile indicated that the

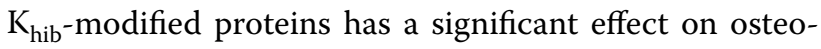
clast function, such as the P00918 (carbonic anhydrase 2, CA2) with four differently $K_{\text {hib }}$-modified sites [1], and the cross-talk between the DEPs and differentially expressed

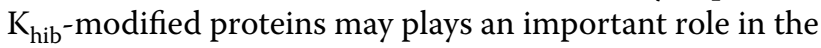
pathogenesis of osteopetrosis.

The changes in DNA methylation profiles suggest epigenetic alteration, which associated with disease susceptibility [44-46], and may be a promising biomarker for clinical applications $[47,48]$. In this study, we found that the DNA methylation levels in the two cell lines were similar, with CpG methylation levels higher than CHG and $\mathrm{CHH}$ methylation levels. Like DNA modification, N6-methyladenosine (m6A) is a novel RNA modification that has been extensively studied in plants and animals [28]. We next obtain the m6A methylation profiles from the two cell lines using MeRIP-seq and RNA-seq method. In this study, 2984 differential m6A peaks were identified, and they were mainly located in 3'UTRs, which is consistent with previous reports [28]. Noteworthy, we observed that the m6A modification levels of ISG15 in ADO2iPSCs is higher than NC-iPSCs in the present study, and its protein expression was also high in the proteomic profile [1], which is involved in regulating the RIG-I-like receptor signalling pathway and bone formation [49]. Further functional analysis of the KEGG pathway indicated that these m6A-modified genes were involved in the Osteoclast differentiation and p53 signalling pathway, which may regulate osteoclast development and differentiation [50, 51]. Furthermore, noncoding RNAs can regulate osteoclast differentiation and function by changing the microenvironment of osteoclastogenesis $[52,53]$.

\section{Conclusions}

In summary, the global multi-omics signatures for ADO2-iPSCs and NC-iPSCs generated in this study represent not only a comprehensive data resource but also provide additional biological insights underlying clinical features of osteopetrosis. In addition, our results indicate that the pathogenesis of ADO2 may begin early in life.

\section{Abbreviations}

ADO2: Autosomal dominant osteopetrosis type II; ADO2-iPSCs: autosomal dominant osteopetrosis type II iPSCs; NC-iPSCs: normal control iPSCs; m6A: N6-methyladenosine; SNPs: single nucleotide polymorphisms; InDels: insertion and deletions; DMRs: Differentially methylated regions; DEMGs: differentially expressed m6A-modified genes; ARO: autosomal recessive osteopetrosis; GO: gene ontology; KEGG: kyoto encyclopedia of genes and genomes; qRT-PCR: Quantitative real-time polymerase chain reaction; ncRNAs: noncoding RNAs;
ceRNA: competing endogenous RNA; DEPs: differentially expressed proteins; DEKMPs: differentially expressed $\mathrm{K}_{\text {hib }}$-modified proteins; HD: human Huntington's disease; CA2: carbonic anhydrase 2.

\section{Supplementary Information}

The online version contains supplementary material available at https://doi. org/10.1186/s41065-021-00204-x.

\section{Additional file 1.}

\section{Acknowledgements}

None.

Code availability

None.

\section{Authors' contributions}

Dai Y, Li CH, Ou ML, and Tang DE conceived and designed the experiments. Tang DE, Shangguan Y, Li CH, Zhu P, and Dai WE prepared the materials and RNA extraction. $\mathrm{Li} C \mathrm{CH}, \mathrm{Ou} \mathrm{ML}$, and Tang DE analyzed the sequencing data and drafted the manuscript. Ou ML, Tang DE and Dai Y critically reviewed the manuscript. All authors read and approved the final manuscript.

\section{Funding}

This study was supported by Science and Technology Planning Project of Guangdong Province, China (No. 2017B020209001), the National Natural Science Foundation of China (No. 81671596), the National Science Foundation for Young Scientists of China (No. 31700795), the science and technology plan of Shenzhen (No. JCYJ20180305163846927), Guangxi Natural Science Foundation (No. 2019JJA140695), Guangxi Natural Science Foundation (NO. 2020GXNSFAA159124) and National Natural Science Foundation of China (NO. 82060393).

\section{Availability of data and materials}

The raw and processed data from small RNA sequencing and ribosomal RNA-depleted sequencing in this study has been deposited with the Gene Expression Omnibus under accession number GSE133937 and GSE140132 respectively. And the raw data from Proteomic profiling has been deposited to the ProteomeXchange Consortium via the PRIDE partner repository with the dataset identifier PXD014227.

\section{Declarations}

Ethics approval and consent to participate

This study was reviewed and approved by the Ethics Committee of Shenzhen People's Hospital (LL-KT-201801127).

All the authors have consent for participation.

Consent for publication

All the authors have consent for publication.

Competing interests

The authors declare that they have no competing interests.

\section{Author details}

${ }^{1}$ Central Laboratory, Guangxi Health Commission Key Laboratory of Glucose and Lipid Metabolism Disorders, The Second Affiliated Hospital of Guilin Medical University, Guilin, Guangxi 541199, People's Republic of China. ${ }^{2}$ Clinical Medical Research Center, Guangdong Provincial Engineering Research Center of Autoimmune Disease Precision Medicine, Shenzhen Engineering Research Center of Autoimmune Disease, The Second Clinical Medical College of Jinan University, The First Affiliated Hospital of Southern University of Science and Technology, Shenzhen People's Hospital, Shenzhen, Guangdong 518020, People's Republic of China. ${ }^{3}$ Guangxi Key Laboratory of Metabolic Disease Research, Central Laboratory of Guilin, NO. 924 Hospital, Guilin 541002, People's Republic of China. ${ }^{4}$ College of Natural Science, University of Texas at Austin, Austin, TX 78712, USA. 
Received: 8 June 2021 Accepted: 8 October 2021

Published online: 27 October 2021

\section{References}

1. Ou M, Li C, Tang D, Xue W, Xu Y, Zhu P, et al. Genotyping, generation and proteomic profiling of the first human autosomal dominant osteopetrosis type II-specific induced pluripotent stem cells. Stem Cell Res Ther. 2019;10(1):251.

2. Maurizi A, Capulli M, Curle A, Patel R, Ucci A, Côrtes JA, et al. Extra-skeletal manifestations in mice affected by Clcn7-dependent autosomal dominant osteopetrosis type 2 clinical and therapeutic implications. Bone Res. 2019;7(1):1-15

3. Zhang Y, Ji D, Li L, Yang S, Zhang H, Duan X. ClC-7 Regulates the Pattern and Early Development of Craniofacial Bone and Tooth. Theranostics. 2019;9(5):1387.

4. Sobacchi C, Schulz A, Coxon FP, Villa A, Helfrich MH. Osteopetrosis: genetics, treatment and new insights into osteoclast function. Nat Rev Endocrinol. 2013;9(9):522.

5. Perdu B, Van Hul W, Van Wesenbeeck L. Osteopetrosis: from Animal Models to Human Conditions. Clin Rev Bone Mineral Metab. 2008;6(3-4):71.

6. Capulli M, Maurizi A, Ventura L, Rucci N, Teti A: Small interfering RNAs as an innovative therapeutic approach for the autosomal dominant osteopetrosis type 2 (ADO2). In: 7th International Conference on Children: 2015: BioScientifica; 2015.

7. Maurizi A, Capulli M, Patel R, Curle A, Rucci N, Teti A. RNA interference therapy for autosomal dominant osteopetrosis type 2. Towards the preclinical development. Bone. 2018;110:343-54.

8. Cabezas-Wallscheid N, Klimmeck D, Hansson J, Lipka DB, Reyes A, Wang $\mathrm{Q}$, et al. Identification of regulatory networks in HSCs and their immediate progeny via integrated proteome, transcriptome, and DNA methylome analysis. Cell Stem Cell. 2014;15(4):507-22.

9. Gao Q, Zhu H, Dong L, Shi W, Chen R, Song Z, Huang C, Li J, Dong X, Zhou Y: Integrated Proteogenomic Characterization of HBV-Related Hepatocellular Carcinoma. Cell 2019, 179(2):561-577. e522.

10. Liu Y, Mi Y, Mueller T, Kreibich S, Williams EG, Van Drogen A, et al. Multiomic measurements of heterogeneity in HeLa cells across laboratories. Nat Biotechnol. 2019;37(3):314-22.

11. Xue R, Chen L, Zhang C, Fujita M, Li R, Yan S-M, Ong CK, Liao X, Gao Q, Sasagawa S. Genomic and transcriptomic profiling of combined hepatocellular and intrahepatic cholangiocarcinoma reveals distinct molecular subtypes. Cancer Cell. 2019;35(6):932-47 e938.

12. Ou M, Zhang X, Dai Y, Gao J, Zhu M, Yang X, et al. Identification of potential microRNA-target pairs associated with osteopetrosis by deep sequencing, iTRAQ proteomics and bioinformatics. Eur J Hum Genet. 2014;22(5):625-32.

13. Coudert AE, Del Fattore A, Baulard C, Olaso R, Schiltz C, Collet C, et al. Differentially expressed genes in autosomal dominant osteopetrosis type II osteoclasts reveal known and novel pathways for osteoclast biology. Lab Invest. 2014;94(3):275-85.

14. Kornak U, Ostertag A, Branger S, Benichou O, de Vernejoul M-C. Polymorphisms in the CLCN7 gene modulate bone density in postmenopausal women and in patients with autosomal dominant osteopetrosis type II. J Clin Endocrinol Metabol. 2006:91(3):995-1000.

15. Sui W, Ou M, Liang J, Ding M, Chen J, Liu W, et al. Rapid gene identification in a Chinese osteopetrosis family by whole exome sequencing. Gene. 2013;516(2):311-5.

16. Alam I, Gray AK, Chu K, Ichikawa S, Mohammad KS, Capannolo M, et al. Generation of the first autosomal dominant osteopetrosis type II (ADO2) disease models. Bone. 2014:59:66-75.

17. Del Fattore A, Gray A, Ichikawa S, Chu K, Mohammad K, Capannolo M, et al. Insertion of the clcn7 gene mutation pG213R in mouse induces autosomal dominant osteopetrosis type II (ADO2). Bone. 2012;6(51):S14

18. Alam I, McQueen AK, Acton D, Reilly AM, Gerard-O'Riley RL, Oakes DK, et al. Phenotypic severity of autosomal dominant osteopetrosis type II (ADO2) mice on different genetic backgrounds recapitulates the features of human disease. Bone. 2017;94:34-41.

19. Caetano-Lopes J, Lessard S, Hann S, Espinoza K, Kang KS, Lim K-E, et al. Clcn7F318L/+ as a new mouse model of Albers-Schönberg disease. Bone. 2017;105:253-61.
20. Okur FV, Cevher I, Özdemir C, Kocaefe Ç, Çetinkaya DU. Osteopetrotic induced pluripotent stem cells derived from patients with different disease-associated mutations by non-integrating reprogramming methods. Stem Cell Res Ther. 2019;10(1):211

21. Lanzi G, Ferraro RM, Masneri S, Piovani G, Barisani C, Sobacchi C, et al. Generation of 3 clones of induced pluripotent stem cells (iPSCs) from a patient affected by Autosomal Recessive Osteopetrosis due to mutations in TCIRG1 gene. Stem Cell Res. 2020;42:101660.

22. Li H, Durbin R. Fast and accurate short read alignment with BurrowsWheeler transform. Bioinformatics. 2009;25(14):1754-60.

23. Li H, Handsaker B, Wysoker A, Fennell T, Ruan J, Homer N, et al. The sequence alignment/map format and SAMtools. Bioinformatics. 2009;25(16):2078-9.

24. Tarasov A, Vilella AJ, Cuppen E, Nijman IJ, Prins P. Sambamba: fast processing of NGS alignment formats. Bioinformatics. 2015;31(12):2032-4.

25. Wang $\mathrm{K}$, Li M, Hakonarson $\mathrm{H}$. ANNOVAR: functional annotation of genetic variants from high-throughput sequencing data. Nucleic Acids Res. 2010;38(16):e164.

26. Martin M. Cutadapt removes adapter sequences from high-throughput sequencing reads. EMBnet J. 2011;17(1):10-2.

27. Chen $H$, Smith AD, Chen T. WALT: fast and accurate read mapping for bisulfite sequencing. Bioinformatics. 2016;32(22):3507-9.

28. Wang Y, Zheng Y, Guo D, Zhang X, Guo S, Hui T, et al. m6A Methylation Analysis of Differentially Expressed Genes in Skin Tissues of Coarse and Fine Type Liaoning Cashmere Goats. Front Genet. 2020;10:1318.

29. Kim D, Langmead B, Salzberg SL. HISAT: a fast spliced aligner with low memory requirements. Nat Methods. 2015:12(4):357-60.

30. Meng J, Lu Z, Liu H, Zhang L, Zhang S, Chen Y, et al. A protocol for RNA methylation differential analysis with MeRIP-Seq data and exomePeak R/ Bioconductor package. Methods. 2014;69(3):274-81.

31. Bailey TL, Boden M, Buske FA, Frith M, Grant CE, Clementi L, Ren J, Li WW, Noble WS: MEME SUITE: tools for motif discovery and searching. Nucleic Acids Research 2009, 37(suppl_2):W202-W208.

32. Heinz S, Benner C, Spann N, Bertolino E, Lin YC, Laslo P, et al. Simple combinations of lineage-determining transcription factors prime cisregulatory elements required for macrophage and B cell identities. Mol Cell. 2010;38(4):576-89

33. Yu G, Wang L-G, He Q-Y. ChIPseeker: an R/Bioconductor package for ChIP peak annotation, comparison and visualization. Bioinformatics. 2015:31(14):2382-3.

34. Pertea M, Pertea GM, Antonescu CM, Chang T-C, Mendell JT, Salzberg SL. StringTie enables improved reconstruction of a transcriptome from RNAseq reads. Nat Biotechnol. 2015;33(3):290.

35. Robinson MD, McCarthy DJ. Smyth GK: edgeR: a Bioconductor package for differential expression analysis of digital gene expression data. Bioinformatics. 2010;26(1):139-40.

36. Schmittgen TD, Livak KJ. Analyzing real-time PCR data by the comparative CT method. Nat Protoc. 2008;3(6):1101.

37. Maurizi A, Capulli M, Patel R, Rucci N, Teti A: A deep phenotyping of autosomal dominant osteopetrosis type 2 (ADO2) mouse model revealed multiorgan dysfunctions. In: 8th International Conference on Children: 2017: BioScientifica; 2017.

38. Chae J-I, Kim D-W, Lee N, Jeon Y-J, Jeon I, Kwon J, et al. Quantitative proteomic analysis of induced pluripotent stem cells derived from a human Huntington's disease patient. Biochem J. 2012;446(3):359-71.

39. Szlachcic WJ, Switonski PM, Krzyzosiak WJ, Figlerowicz M, Figiel M. Huntington disease iPSCs show early molecular changes in intracellular signaling, the expression of oxidative stress proteins and the p53 pathway. Dis Model Mech. 2015;8(9):1047-57.

40. Tang D, Chen Y, He H, Huang J, Chen W, Peng W, et al. Integrated analysis of mRNA, microRNA and protein in systemic lupus erythematosus-specific induced pluripotent stem cells from urine. BMC Genomics. 2016;17(1):488

41. W-b C, J-r H, Yu X-q, Lin X-c. Dai Y: Identification of microRNAs and their target genes in Alport syndrome using deep sequencing of iPSCs samples. J Zhejiang University-Sci B. 2015;16(3):235-50.

42. Wang Z, Moult J. SNPs, protein structure, and disease. Hum Mutat. 2001;17(4):263-70.

43. Waguespack SG, Hui SL, DiMeglio LA, Econs MJ. Autosomal dominant osteopetrosis: clinical severity and natural history of 94 subjects with a chloride channel 7 gene mutation. J Clin Endocrinol Metabol. 2007:92(3):771-8. 
44. Reinius LE, Acevedo N, Joerink M, Pershagen G, Dahlén S-E, Greco D, Söderhäll C, Scheynius A, Kere J. Differential DNA methylation in purified human blood cells: implications for cell lineage and studies on disease susceptibility. PLoS One. 2012;7(7):e41361.

45. Jenkins TG, Aston Kl, Pflueger C, Cairns BR, Carrell DT. Age-associated sperm DNA methylation alterations: possible implications in offspring disease susceptibility. PLoS Genet. 201410(7):e1004458.

46. De Jager PL, Srivastava G, Lunnon K, Burgess J, Schalkwyk LC, Yu L, et al. Alzheimer's disease: early alterations in brain DNA methylation at ANK1, BIN1, RHBDF2 and other loci. Nat Neurosci. 2014;17(9):1156-63.

47. Tost J. DNA methylation: an introduction to the biology and the disease-associated changes of a promising biomarker. Mol Biotechnol. 2010:44(1):71-81.

48. Ju Z, Jiang Q, Wang J, Wang X, Yang C, Sun Y, Zhang Y, Wang C, Gao Y, Wei $X$. Genome-wide methylation and transcriptome of blood neutrophils reveal the roles of DNA methylation in affecting transcription of protein-coding genes and miRNAs in E. coli-infected mastitis cows. BMC Genomics. 2020;21(1):102.

49. Albers J, Schulze J, Beil FT, Gebauer M, Baranowsky A, Keller J, et al. Control of bone formation by the serpentine receptor Frizzled-9. J Cell Biol. 2011;192(6):1057-72.
50. Kim JH, Kim N. Signaling pathways in osteoclast differentiation. Chonnam Med J. 2016;52(1):12-7.

51. Huang H, Chang E-J, Ryu J, Lee ZH, Lee Y, Kim H-H. Induction of c-Fos and NFATC1 during RANKL-stimulated osteoclast differentiation is mediated by the p38 signaling pathway. Biochem Biophys Res Commun. 2006;351(1):99-105.

52. Liang W-C, Fu W-M, Wang Y-B, Sun Y-X, Xu L-L, Wong C-W, et al. H19 activates Wnt signaling and promotes osteoblast differentiation by functioning as a competing endogenous RNA. Sci Rep. 2016;6:20121.

53. Dou C, Cao Z, Yang B, Ding N, Hou T, Luo F, et al. Changing expression profiles of IncRNAs, mRNAs, circRNAs and miRNAs during osteoclastogenesis. Sci Rep. 2016;6(1):1-12

\section{Publisher's Note}

Springer Nature remains neutral with regard to jurisdictional claims in published maps and institutional affiliations.
Ready to submit your research? Choose BMC and benefit from:

- fast, convenient online submission

- thorough peer review by experienced researchers in your field

- rapid publication on acceptance

- support for research data, including large and complex data types

- gold Open Access which fosters wider collaboration and increased citations

- maximum visibility for your research: over $100 \mathrm{M}$ website views per year

At BMC, research is always in progress.

Learn more biomedcentral.com/submissions 